\title{
Pioneer of hyaluronan structural chemistry and other studies of polysaccharides: Torvard C. Laurent (1930-2009)
}

\author{
István Hargittai
}

Published online: 7 April 2010

(C) Springer Science+Business Media, LLC 2010

\begin{abstract}
Torvard C. Laurent (1930-2009) was one of the pioneers of hyaluronan science and in particular of its structural aspects. He was the first who ever established the metrical characteristics of hyaluronan. He determined many of its physicochemical properties and their relationship to the versatile biological functions of this noted molecule. He also contributed to its medical applications. He was a leading personality in science administration and science policy in Sweden and internationally.
\end{abstract}

Keywords Torvard C. Laurent - Hyaluronan ·

Macromolecular structures .

X-ray studies of amorphous bodies .

Structure and biological function

\section{I believe that a lot of the future of the biological function can be revealed by studies of protein-hyaluronan complexes. Torvard C. Laurent, 2003 [1]}

Torvard C. Laurent (Fig. 1) was born in 1930 in Stockholm into an academic family. Of his family's history, he especially revered his great-grandfather, Carl-Erik Bergstrand

This Editorial was being prepared simultaneously with a more detailed commemorative chapter, Hargittai I (2010) Torvard C Laurent, In Hargittai M, More conversations with hyaluronan scientists. Volume 2 in Balazs EA, General Editor, Hyaluronan: From Basic Science to Clinical Applications, PubMatrix, Edgewater, NJ (to be published).

\section{Hargittai ( $\square)$}

Department of Inorganic and Analytical Chemistry, Materials Structure and Modeling Research Group of the Hungarian Academy of Sciences, Budapest University of Technology and Economics, P.O. Box 91, Budapest 1521, Hungary e-mail: istvan.hargittai@gmail.com

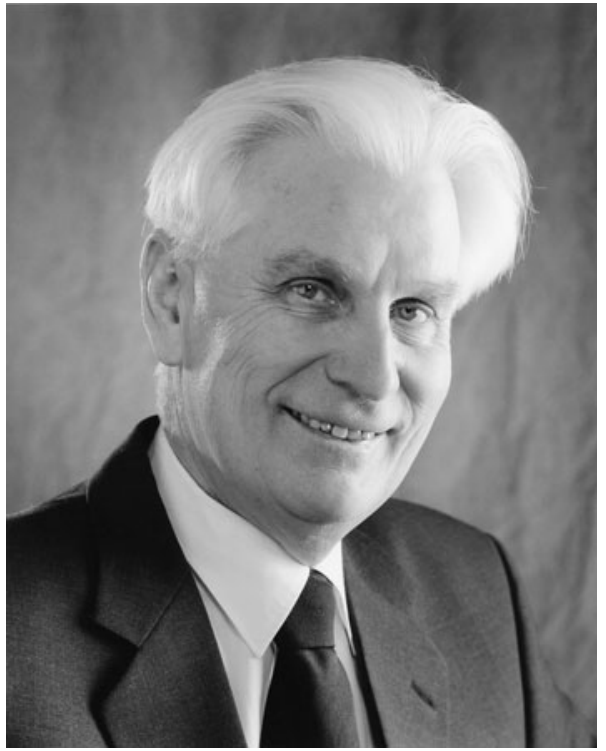

Fig. 1 Torvard C. Laurent in 2002 (photograph by Birgitta Hellsing; all photographs courtesy of the late Torvard C. Laurent and Agneta Laurent, Stockholm)

(1830-1914) who became Professor of Agricultural Chemistry in 1864 and taught at Ultuna, which was the predecessor of today's Swedish Agricultural University. In the period of 1869-1882, he was in charge of the Chemical Research Station of the Academy of Agricultural Sciences in Stockholm. His principal research area was in fertilizers. In order to expand his knowledge and gain experience, he visited German and Austrian laboratories in 1859 [2]. Laurent learned about his great-grandfather's life and activities from his diary. Laurent's aunt, Vivi Täckholm, was a professor of botany at Cairo University and was probably the best known among his relatives [3]. When Laurent was a teenager, he collected many plants for her in 
Sweden, and these plants are now in the herbarium in Cairo.

Laurent entered medical school at the Karolinska Institute in 1948 and had illustrious teachers, among them Einar Hammarsten and Erik Jorpes who were already established scientists by then, and Peter Reichard who was only 5 years his senior. It happened during the second year of Laurent's studies that Hjalmar Holmgren, Professor of Experimental Histology of the Karolinska Institute, invited him to be an unpaid instructor of histology. Laurent met Endre Balazs in Holmgren's laboratory, and started working with him in 1949.

Laurent prepared polysaccharides from tissues, and in particular, hyaluronic acid-today known as hyaluronan. In fact, Laurent was one of the three researchers who suggested this change in the nomenclature [4]. His source of hyaluronan was umbilical cord, which is rich in hyaluronan, and Laurent picked up the umbilical cords from the hospital, and extracted hyaluronan from them in his laboratory. During this work, he made several interesting observations. Different salt concentrations were used at varying $\mathrm{pH}$ values to extract hyaluronan, and Laurent found highly different viscosities of the extracts obtained under different conditions. At first, he thought that the different procedures were not equally effective, but it turned out that the viscosity of hyaluronan depended considerably on the $\mathrm{pH}$ of the solution and its ionic strength. This observation led to his first publication.

Another observation resulted from the attempts to sterilize the polysaccharide after filtration had failed due to the high viscosity of the substance. When hyaluronan was irradiated by ultraviolet light though, its high viscosity greatly diminished. Only later did they learn that this was due to the degrading impact of irradiation, which generated hydroxyl-free radicals that attacked the polysaccharide chain. This observation was the first detection of free radical degradation of hyaluronan. However, at that time, they did not try to find an explanation for it; they only recorded their observations. From this work, another publication emerged. There was yet a third observation according to which sulfated "hyaluronan" showed enzyme-inhibiting activities and impacted cell growth. They showed that sulfated "hyaluronan" was heparan sulfate and described its biological effects. This led them to a third publication [5]. Laurent thus jump-started his research career while doing his undergraduate studies.

Soon Laurent's mentor, Balazs, left for the United States, Professor Holmgren died of cancer, and Laurent moved to the Chemistry Department of the Karolinska Institute. He started working with Hammarsten who was a very informal person, but greatly influential in Swedish academia. Laurent's direct interaction was with Bertil Jacobson, a physical chemist who was especially skilled in building instruments and who eventually became professor of medical technology.

Laurent started doing structural studies under Jacobson's direction. He calculated intermolecular distances in organic liquids and correlated them with viscosities. There was great interest in DNA at the time, and Laurent's interest in hyaluronan complemented Jacobson's interest in DNA-both substances being biopolymers. Laurent interacted with Sven Gardell who was an expert in polysaccharide chemistry. Gardell could separate and analyze the polysaccharide components of connective tissues. Others succeeded in isolating a factor in serum that enhanced sulfate incorporation into cartilage, which was then showed to be glutamine. Thus Laurent was surrounded by a sizzling research atmosphere at the Chemistry Department of the Karolinska Institute.

Laurent was so much taken by the emerging research opportunities that even before finishing medical school he joined Balazs at the Retina Foundation in Boston for the period of 1953-1954. Laurent's fiancée, Ulla, soon joined him, and they married in New York soon after. Eventually, Ulla Laurent became a noted ophthalmologist. Still in Boston, Laurent learned a new technique, light-scattering, from John Gergely who was a biochemist at Massachusetts General Hospital at the time. Laurent then did measurements of light scattering of various hyaluronan samples and showed that hyaluronan had a molecular mass of several million Dalton, and that its behavior was that of a stiff random coil in solution. These light-scattering studies done with Gergely became the core of his doctoral thesis [6] (Fig. 2).

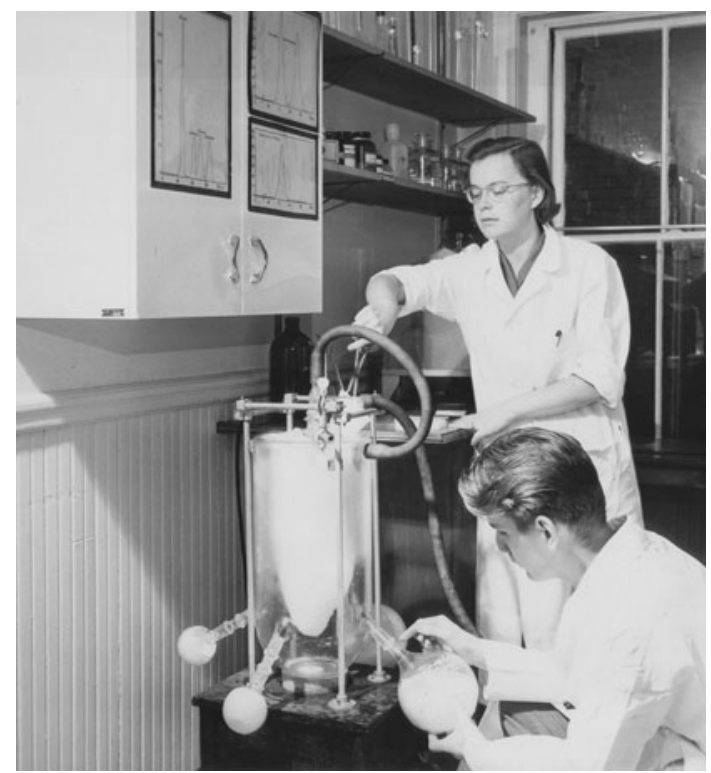

Fig. 2 Torvard and Ulla Laurent conducting an experiment at the Retina Foundation in Boston in the early 1950s 
After a year and a half, the Laurents returned to Stockholm and Laurent resumed his studies at the medical school. Parallel with completing his course work, he continued doing research and Jacobson directed him to get acquainted with the X-ray diffraction technique of macromolecular structures. Laurent conducted experiments on aqueous solutions of DNA as well as on hyaluronan. The DNA studies stemmed from Jacobson's interest and ultimately did not support Jacobson's suppositions about the structure of DNA solutions. The structural studies on hyaluronan, though, proved to be unique and their results of long-lasting value.

Laurent's X-ray diffraction experiments used an amorphous hyaluronan sample. At the time this was a state-ofthe-art investigation, and the interpretation of the data could hardly be made better today, over half a century later. He prepared samples under different conditions in order to avoid artifacts due to any specificities of the conditions under which he obtained them. He derived his direct structural information from the radial distributionsessentially a probability density distribution of the interatomic distances, both intramolecular and intermolecular in this case [7]. The metric dimensions he extracted from his measurements have not been superseded ever since [8].

Hammarsten was very helpful to Laurent in this period. He helped him acquire a light-scattering photometer and arranged a teaching position for him even before the completion of his studies. Laurent made a thorough investigation of the properties of hyaluronans isolated from different tissues. His international outlook was expanding, and he learned about a new technique to isolate and fractionate polyanions, which was published by John Scott in Manchester. Scott used detergents, especially cetylpyridinium chloride (CPC), for the precipitation of polymers, and utilized the fact that differently charged polymers precipitated at different ionic strengths, which provided a tremendous methodological advantage. This readily separated hyaluronan from the other sulfated glycosaminoglycans.

Laurent successfully used the new approach, and produced additional evidence for his previously described model of hyaluronan as a random coil structure. In addition, he studied, for the first time, hyaluronan as dissolved in an organic solvent, when he succeeded in dissolving a CPChyaluronate complex in methanol. Laurent defended his dissertation at the Karolinska Institute in 1957. Its title was "Physico-Chemical Studies of Hyaluronic Acid." About half a year later, he was also awarded his medical degree.

In 1959, the Laurents returned to the Retina Foundation in Boston and stayed there for two and a half years. Laurent continued his physical chemistry and the main thrust of his research was the investigation of the physiological function of polysaccharides in connective tissues. One of his many results from this period was the observation that the anti-coagulant activity of heparin was molecular weight-dependent. Another area of fruitful studies by Laurent and his colleagues was the properties of hyaluronan networks at physiological concentrations. They made their first observations in ultracentrifuge experiments, and Laurent reasoned that the same properties must play a role in the extracellular matrix between the cells. Accordingly, the holes in the hyaluronan network should regulate the transport of other molecules, which would make hyaluronan a molecular sieve, retarding large molecules more than smaller ones [9]. They even succeeded in producing a quantitative description of size retardation as a function of network density.

Laurent returned to Sweden in 1961. He arrived at a fortunate time to start anew, because the universities were expanding, and he succeeded in quickly building up his research. The professor of medical and physiological chemistry at Uppsala University, Gunnar Blix, had just retired, but continued his research and was supportive of Laurent and so was his successor, Peter Reichard, who had been Laurent's chemistry instructor at the Karolinska. Laurent received support from the Swedish Medical Research Council as well. His experience in eye research at the Retina Foundation contributed to his interactions with Ernst Bárány, the professor of pharmacology, who worked next door and whose research specialty was eye physiology. He was widely respected in the Faculty of Medicine and Laurent could always rely on him for advice. There was a lot of interdisciplinary cross-fertilization of research at Uppsala favoring creativity, and Laurent and his research thrived under these conditions.

It was at this time, too, that Laurent initiated an exceptionally fruitful interaction with one of the greats of the polysaccharide field, Alexander G. "Sandy" Ogston of Oxford University [10]. The impetus of their interactions was the experiments involving equilibrium dialysis carried out independently by the two research groups. The discrepancies between the two sets of data and Ogston's sound theoretical contributions brought them together. The principal findings of these studies confirmed that polysaccharides manifest a very large exclusion effect on proteins.

Laurent utilized Ogston's model of the exclusion effect for explaining various phenomena in connection with the application of gel filtration techniques. The essence is that due to molecular exclusion, large molecules are eluted before smaller molecules when proteins are chromatographed on granulated cross-linked gel. Laurent's and Johan Killander's paper describing their findings became Laurent's most cited publication (as of now, it has been cited at least 1,736 times and is still being frequently cited) [11].

Independent evaluations have noted the importance of the interactions between Ogston and Laurent in the studies of concentrated solutions of biopolymers [12]. The 


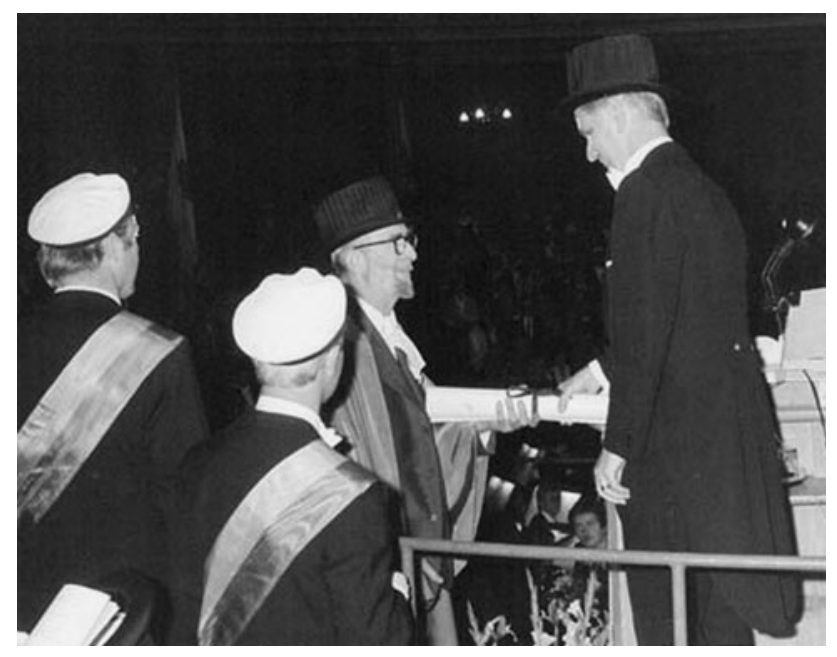

Fig. 3 Alexander Ogston receiving an honorary doctorate from Torvard Laurent during the celebrations of the 500th anniversary of Uppsala University in 1977

molecular exclusion phenomenon of hyaluronan and proteoglycan complexes is sometimes referred to as the "Ogston-Laurent effect" [13], and it is manifested in phase separation, osmotic pressure, aggregation, solubility, in molecular partition phenomena, and elsewhere.

Laurent was involved in Ogston's extensive studies that provided evidence for the validity of the exclusion theory. For this purpose, measurements of osmotic pressure were carried out in mixed solutions of proteins and hyaluronan. In this connection Laurent and Ogston did a follow-up work to previous observations in Ogston's group on solutions of polysaccharides and buffers. They found that the osmotic pressure of the solutions containing a mixture of hyaluronan and serum albumin exceeded the sum of osmotic pressures of the respective individual solutions. Consideration of osmotic pressure was another approach to assess the physiological function of hyaluronan based on its physicochemical properties [14] (Fig. 3).

We have already seen that Laurent learned X-ray crystallography in order to determine the metrical aspects of the structure of hyaluronan. This was by far not his only attempt to contribute to the knowledge about the structural aspects of hyaluronan. Curiously, the much utilized and increasingly popular polysaccharides still have some unknown territory for rigorous structural information [8]. Of course, it was yet more so in the 1960s when Laurent made another attempt to learn more about it. The composition of hyaluronan itself was determined in the late 1940s and early 1950s. It was established that it was an unbranched polymer of a disaccharide, hyalubiuronic acid, consisting of D-glucuronic acid and $N$-acetyl-D-glucosamine. These two sugars are linked by $\beta(1-3)$ and $\beta(1-4)$ bonds [15]. Recent quantum chemical studies probed into the comparison of these two bonding arrangements [16].
Whereas there has been a general consensus in the literature about the unbranched nature of hyaluronan as a polymeric substance, the notion is also widespread that it has a great affinity toward forming networks of chains [17]. Of course, whether it is called branching or network-formation between polymers is to some extent a question of semantics unless it is discussed rigorously on the basis of differences in relative bond strengths. The branching versus not-branching dilemma may have important consequences in understanding the medical applications of hyaluronan.

As early as 1964, Laurent and his co-workers pioneered a cross-linking experiment with hyaluronan [18]. They used a simple yet efficient procedure to link hyaluronan chains thereby creating larger molecules of higher molecular mass that were essentially gels. They succeeded in accomplishing their goals without any appreciable destruction of the amino and carboxylic groups of the initial polymers. Laurent's further studies were directed at uncovering the interactions between hyaluronan and other biological macromolecules. He concluded that the hyaluronan gels excluded proteins and other globular particles to such a considerable extent that could only be interpreted by the presence of a three-dimensional network of fairly rigid single chains. The results could not be interpreted by an extensive double helix, neither by other aggregated conformations of hyaluronan. This was yet another important piece of information in the realm of knowledge about the structural aspects of hyaluronan.

In the mid-1960s, Laurent had accumulated a sufficient amount of new information that he could present wellreceived comprehensive reviews of the correlations between the physical-chemical properties and the biological function of polysaccharide networks. Thus, he related anomalous osmotic pressure to regulation of hydration of tissues; flow resistance to regulation of flow through tissues; variations in solubility of macromolecules to precipitations in tissues; retardation of diffusion of macromolecules to macromolecular transport in tissues; and viscoelasticity to lubrication phenomena.

This was also the time when he was appointed to the prestigious chair of medical and physiological chemistry of Uppsala University, a position that he occupied until his retirement. The next dozen years saw a transition in the character of Laurent's activities. Their emphasis shifted from research to administrative duties and to establishing and implementing science policy. In addition to being involved in matters at his own department and his own university, he was appointed onto two research councils for the whole country; one for science and the other for medicine. It was still an exceptional period for Sweden as science and academia continued expanding, and he realized the grave responsibility of utilizing the considerable funds 
at their disposal in the best possible ways. At the same time, Laurent did not cease to be involved in research either; but with less hands-on participation and more direction of the activities of his graduate students. They were invariably of high quality who have become professors at Swedish and international universities. There were also visiting scientists and excellent technicians contributing to the scientific activities of Laurent's department.

As early as 1965, Laurent had already in mind going to Australia where the main attraction for him was Sandy Ogston who had moved there from Oxford. However, when Laurent was appointed to the Uppsala chair, his Australia project was shelved. Ogston himself came to Uppsala in 1972, and this was the beginning of intensive interactions for Laurent with Australian scientists. They continued after Ogston had left Australia and returned to Oxford. Laurent's principal co-worker in Australia was Barry N. Preston who also spent some time in Uppsala with Laurent. His other close collaborators were Robert L. Cleland and Lars-Olof Sundelöf. There were many other scientists from different places who worked with Laurent during this period. There was a very active research atmosphere in his laboratory in spite of his many-faceted administrative duties.

When those administrative duties nonetheless became overwhelming, Laurent decided to have a break, and he and his wife departed for Australia for a sabbatical year. His visit was preceded by Preston's stay in Uppsala during which their joint investigation on transport phenomena in concentrated polymeric solutions was initiated. This work intensified during Laurent's sabbatical at Monash University in Clayton, Victoria. Previously, he had made an interesting observation, which was about high-molecularweight polyvinyl pyrrolidone (PVP). He found that this polymer "diffused" rapidly through dextran solutions, much more rapidly, that is, than, for example, glucose. It was puzzling, and the term "diffused" was put in quotation marks here, because a subsequent discovery determined that the nature of movement was not at all diffusion.

In order to understand the phenomenon, they did the following experiment. They had tritium-labeled PVP of molecular mass of $300000 \mathrm{Da}$ and ${ }^{14} \mathrm{C}$-labeled glucose in a dextran solution, and layered another dextran solution on top; they then observed an enormous difference in the upward transport of the different components. They explained what they saw by supposing that the large PVP molecules were excluded in the concentrated dextran solution and an enhanced chemical activity provided the driving force for their rapid movement. It was, however, not an unambiguous interpretation and it seemed difficult to arrive at a satisfactory explanation.

They found a successful solution in the idea that they could stain the PVP component blue, and this made it possible to follow the changes with their naked eyes. What

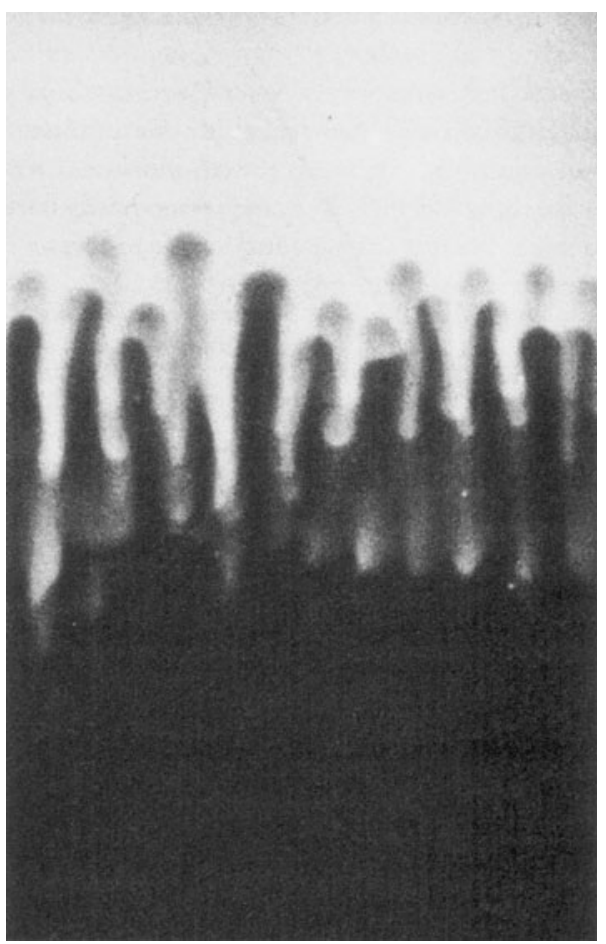

Fig. 4 Structured flow in which PVP had been stained with a dye to make it visible [22, p 333]. Reproduced with permission

they observed was nothing short of spectacular. The PVP moved up in regular finger shapes through the top solution (Fig. 4).

There was an ordered convection in the system, which could be explained by the PVP increasing the osmotic pressure, with the bottom solution taking up water from the dextran solution at the top, and the resulting density inversion inducing convection. The upward movement of the PVP fingers is driven osmotically. In contrast, the glucose is transported by countercurrent distribution between fingers moving upward and downward, and as a result it stays still. Even many years later, Laurent was still very happy about this discovery and called it "a truly unexpected discovery, the kind one makes once in a lifetime" [19]. They published a report about it in Nature, and the magazine displayed the blue PVP fingers on its cover [20]. Upon closer examination, what they observed was interpreted by the formation of symmetric rod-like (finger) structures in the dextran solutions. As these fingers grew vertically, they carried high-molecular-mass material through the system. A possible interpretation advanced by Laurent and his co-author, Lars-Olof Sundelöf, is shown in Fig. 5.

Laurent liked to use this finding as an example of how unexpected discoveries may be made emerging from research originally aimed at different goals. Often the unexpected results have a bearing on other fields more than 


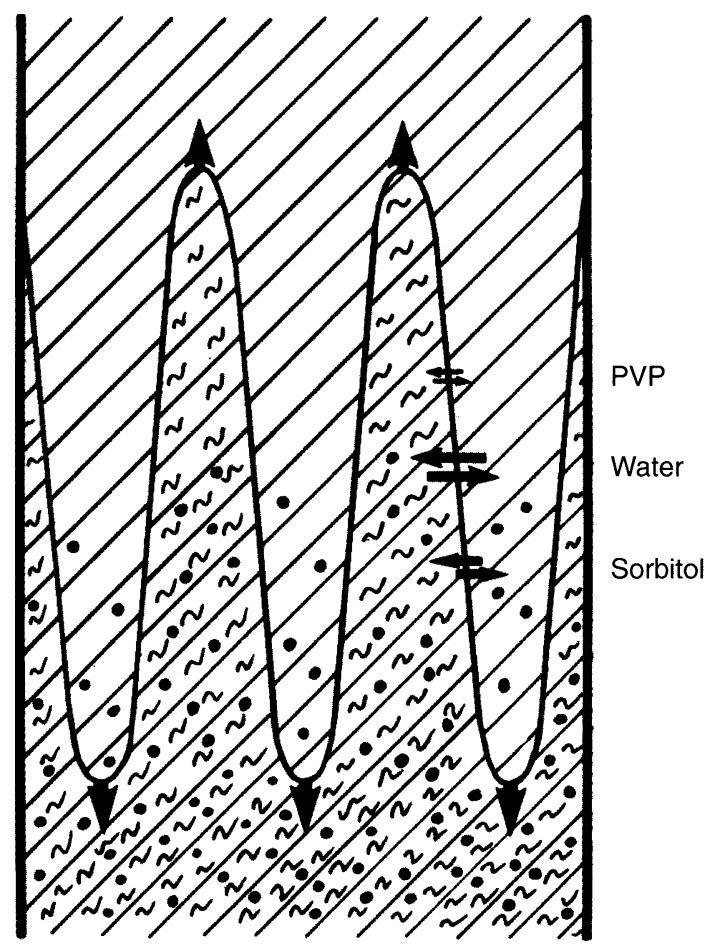

Fig. 5 Possible interpretation of the structured flow of PVP, that is, the different transport rates by ordered convective flow: "Water diffuses freely between the ascending and descending fingers. Due to osmotic forces there is a small positive water flux from descending structures. Sorbitol also moves relatively freely between the structures and is therefore affected little by the structured flow. PVP is essentially confined to the ascending structures and moves rapidly through the system." [22, p 334]. Reproduced with permission

on the one where they had been produced. In this case, he viewed their discovery as having interest in how symmetrical, ordered structures might be formed in Nature. It is also true that over the years he became somewhat disappointed in the follow-up life of this discovery, because the original question in their study, viz., the one about the mechanism of macromolecular transport in tissues, has not been answered. It does not seem probable that such transport by ordered convection is characteristic of biological systems.

Upon returning to Sweden, Laurent continued his manyfaceted activities in which research still occupied a conspicuous component. This was now a period in which his investigations branched out in new directions, well beyond the realm of the physical chemistry of polysaccharides. In 1980 , one of his graduate students developed a technique to determine hyaluronan in nanogram amounts, which made its determination possible in all tissues. It was still in Australia that Ulla Laurent had shown that there were small amounts of hyaluronan in blood that came from peripheral tissues via the lymph. Acting upon this observation, Fraser injected radioactive hyaluronan into rabbits and examined the time it took for hyaluronan to disappear from blood. It disappeared with a half-life of 2 to $5 \mathrm{~min}$. The hyaluronan from blood went into the liver, and this was the beginning of a big project of investigating the turnover of polysaccharides in various organs of organisms. The liver turned out to be a general receiving organ, and they even found the hyaluronan receptor there that removes hyaluronan from the blood.

These studies led to findings of clinical importance, and a diagnostic tool was also developed subsequently. Thus, for example, if there is high concentration of hyaluronan in blood, it points to liver disease, especially to the defects of specific cells for which no test had existed. Liver cirrhosis is always accompanied by high serum hyaluronan concentration. However, liver disease may not be the only pathological change associated with high serum hyaluronan concentration. It may also be an indication of rheumatic arthritis. Joints contain a large amount of hyaluronan, and when they move, they pump hyaluronan out into the lymphatics and into blood. The variations of hyaluronan concentration in blood may tell us a great deal about the conditions of the joints. This area was a fruitful ground for Laurent's and his associates' research. In the last decades of his active research life his pupils had spectacular successes in the fields of heparin, cell-cell and cell-matrix adhesion, platelet-derived growth factor, and many others. Scientists who had received their training in Laurent's laboratory became leading contributors to biological and medical chemistry all over Sweden and some internationally.

In 1982, Laurent was elected to be a member of the Royal Swedish Academy of Sciences, one of the world's most prestigious scientific societies. In 1991, he was then elected to be its president and he discharged his duties with dedication and success. One of the most conspicuous activities of this Academy is the awarding of the Nobel Prizes in Physics and in Chemistry and also of the prize in

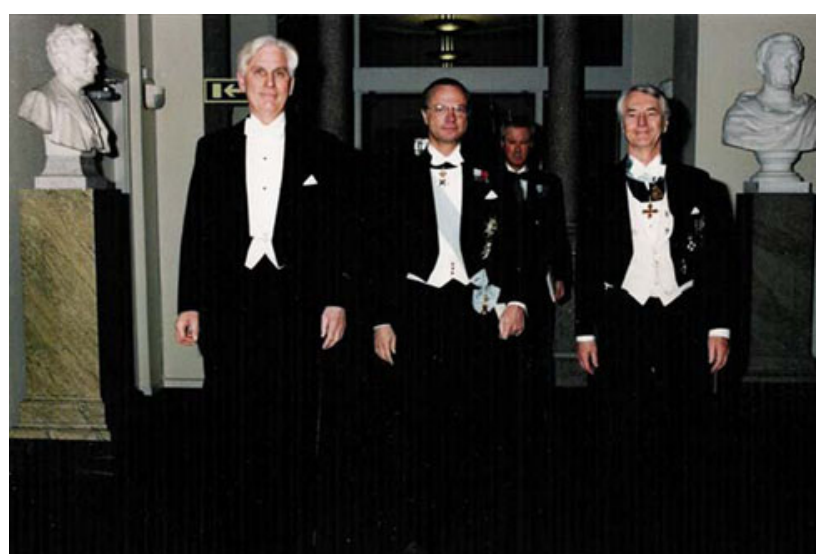

Fig. 6 Carl XVI Gustaf, King of Sweden (middle), Torvard Laurent (left) as President, and Carl-Olof Jacobson (right) as permanent secretary of the Royal Swedish Academy of Sciences (photograph by Lars Falck) 


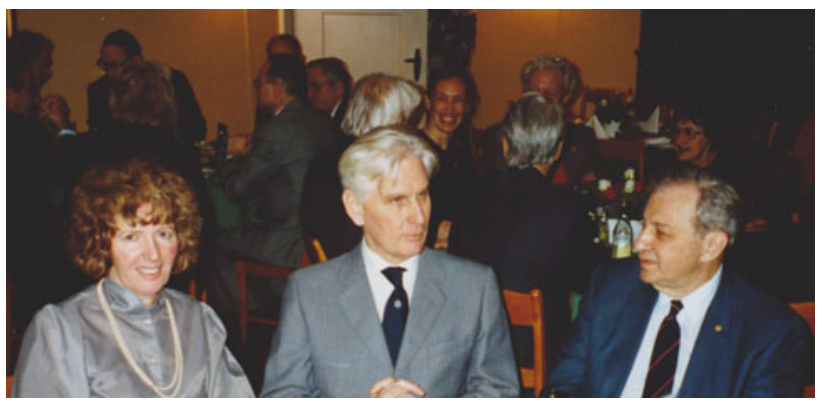

Fig. 7 From left to right Cecilia Jarlskog, long-time member of the Nobel Committee of Physics, Torvard Laurent, and Rudolph A. Marcus, Nobel laureate (1992) in Chemistry on December 7, 1992, at the Royal Swedish Academy of Sciences (photograph by Lars Falck)

Alfred Nobel's memory in Economics. Although the academy presidency is limited to a single 3-year term, he continued wielding great respect and influence in matters of the Academy after his presidency was over in 1994 (Figs. 6 and 7).

My wife and I were indirect beneficiaries of Laurent's influence when I was invited to give a lecture at the Academy on the day of the announcement of the 1996 physics and chemistry prizes. This is a tradition that there is a scientific lecture on the day of the announcement and

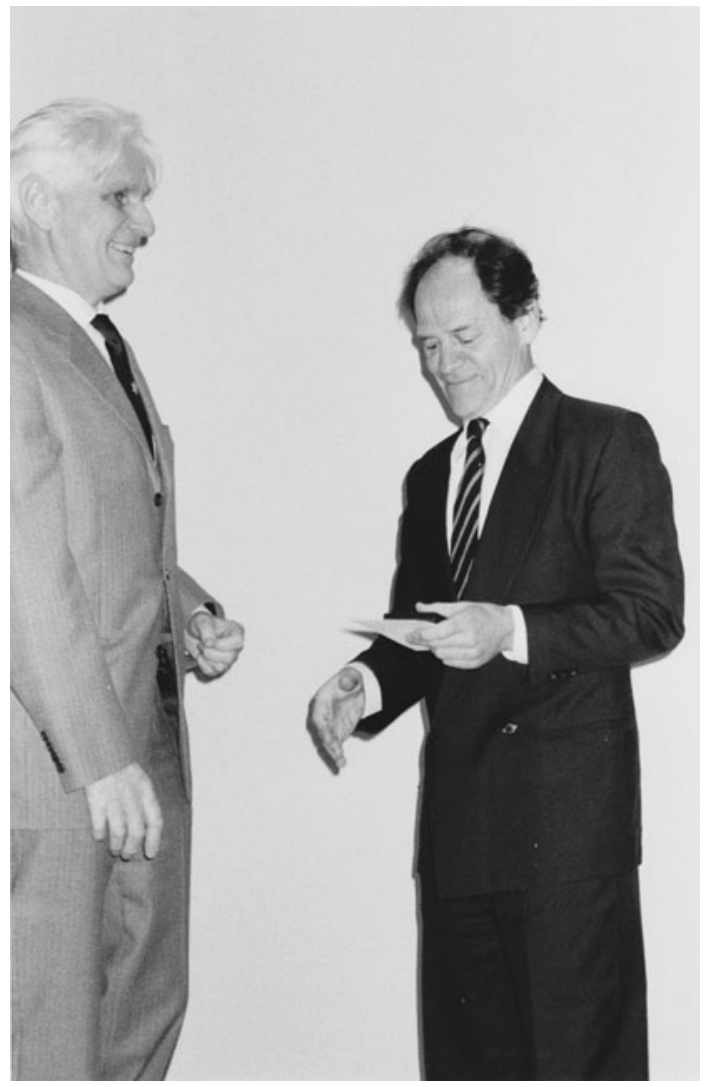

Fig. 8 Torvard C. Laurent with Torsten N. Wiesel, Nobel laureate (1981) in Physiology or Medicine (photograph by Lars Falck) my lecture topic - symmetry - was closely related to both the physics and chemistry prizes in 1996, especially in chemistry since the award went for the discovery of buckminsterfullerene. I was again invited to give a lecture at the Academy in 2001, and the circumstances were yet even more conspicuous. The timing was the week of the award-giving ceremonies and the celebrations of the Nobel centennial. The topic of my lecture on this occasion was the Nobel Prize itself. Attending the ceremonies was an adventure of a lifetime, and the interest in what I had to say about the Nobel Prize greatly encouraged me in completing my book about the award [21].

During his academy presidency Laurent traveled a lot, built contacts for the Academy, and represented it and his country on various occasions. He discharged his duties with zest and great success. He did not refrain from exercising some humor even in his most official functions. On one occasion when he introduced Carl Djerassi as speaker at the Academy, he expressed his regret that Djerassi never won the Nobel Prize, which he could have won even in two, not just one, disciplines-chemistry and medicine. Laurent, as a consolation, awarded him the only prize he exercised full control over, and that was the peas-prize, and he handed Djerassi a can of green peas wrapped in a Swedish flag. If Djerassi was upset by the somewhat cruel nature of the joke-because Djerassi rightly could be disappointed from being omitted from the roster of Nobel laureates-he did not show it, and took the joke with sufficient grace.

The presidency of the Science Academy suited Laurent's independent personality eminently. The Science Academy in Sweden is a fully autonomous organization, which finances itself and receives very little subsidy from

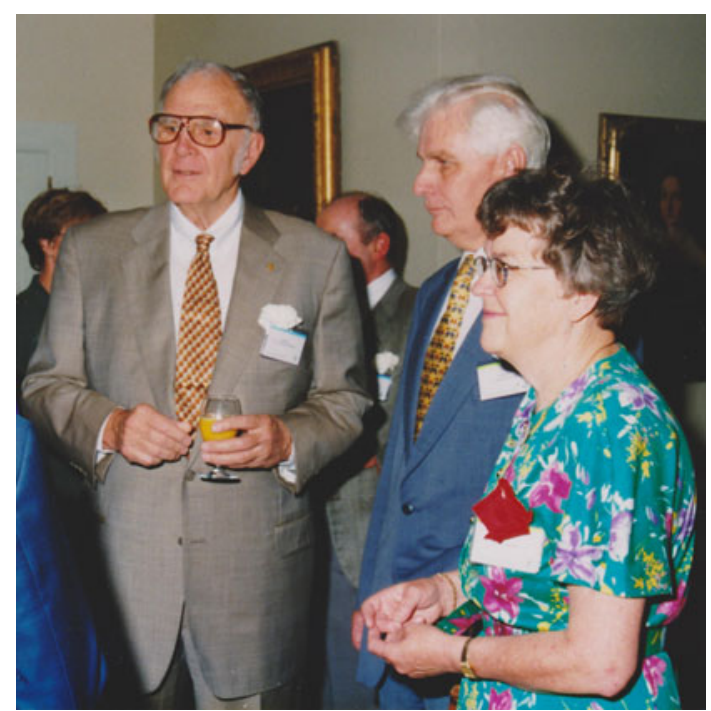

Fig. 9 Torvard and Ulla Laurent with F. Sherwood Rowland, Nobel laureate (1995) in Chemistry 
the government. It gives advice, but does not take orders. The Royal Swedish Academy of Sciences is primarily a body of scientists and runs very few research institutions. They start something like that only when there is a new field and the Academy has a greater flexibility than government organizations to enter it. However, once the field becomes well established, they transfer the institution to the state or to a university. This way they do not run out of their resources and are always prepared to respond to new challenges. Laurent was happy to pursue such a policy.

It was during his presidency that he was elected member of the Nobel Committee of Chemistry, and he served on this committee for 9 years. His membership on this committee was meant to bring in more expertise from medical chemistry and biochemistry, and whether it was Laurent's impact or not-and it could not have been his alone-a relatively large proportion of the chemistry Nobel Prizes lately have gone for discoveries in biological chemistry and related areas (Figs. 8 and 9).

Another involvement in academic affairs of science policy nature was Laurent's participation in the work of the Nobel Foundation. He became member of the Board of Trustees in 1992, and served as its chairman in the period of 1994-2001. It was a very prestigious position, which seemingly did not take much of his time-there was only one regular meeting annually_but the responsibilities were considerable, and he had to meet and talk with many other people having also responsible positions. He was a much sought-after officer of science-related organizations and a similarly much sought-after speaker, and, gradually, he grew to like these involvements.

It is no wonder that his duties multiplied in the early 1990 s, because when he formally retired from the university and became professor emeritus, he was still in his full capacities, and he was ready and willing to serve. In 1992, he joined the board of the Wenner-Gren Foundation, and he became its scientific secretary in 1993. Thus there was some overlap between his functions of being President of the Royal Swedish Academy of Sciences and the responsibility at the foundation. The Wenner-Gren Foundation was started in the mid-1950s, and it blossomed when Laurent took over. He and his colleagues were responsible for dispersing large amounts of money-millions, in terms of U.S. dollars-annually in support of science. Perhaps the centerpiece of the Wenner-Gren programs is their postdoctoral fellowship project. One of the other projects is the Distinguished Wenner-Gren Lectureship, which brings annually two or three lecturers to Sweden who then perform an extended program and lecture not only in Stockholm but in other university centers as well. A considerable proportion of the lecturers traditionally are invited from France. In 1996, Marianne Grunberg-Manago of the French Academy was invited, and it was that year when I had also this honor and went for my first visit to Sweden and delivered lectures in a series of locations.

Another project of the Wenner-Gren Foundation was the organization of international symposia. It had been an ongoing project when Laurent took over, but whereas his predecessor limited the topics of the symposia to a narrow circle of interest, Laurent considerably broadened it. This is how it happened that in the year 2000, he and I jointly organized a symposium on symmetry involving the widest possible circle of participants from science and mathematics to the arts and to the humanities. As is often the case with the Wenner-Gren symposia, it was followed by the publication of a book-in our case it was a two-volume treatise-a truly interdisciplinary project [22]. One of the other symposia and subsequent volumes dealt with the chemistry and biology as well as the medical applications of hyaluronan [23].

Our joint work in organizing the Symmetry 2000 symposium and in editing the subsequent two-volume treatise under the same title gave me a rare glimpse at Laurent beyond the scientist of a rather narrow specialization. $\mathrm{He}$ indulged in interacting with scientists and artists and handling their contributions of the most diverse disciplines. However, this was not quite unexpected for me because during the previous years he showed me his interest in science history and even in history in a broader sense. In this the influence of his great-grandfather, Carl-Erik Bergstrand could be detected.

Laurent and I talked about the beautiful square in Stockholm, Humlegården, with statues of two outstanding representatives of Swedish science. One of them is the Linnaeus statue. Carl Linnaeus, or Carl von Linné (17071778), was a great Swedish naturalist; August Strindberg wrote about him that he was in reality a poet who happened to be a naturalist. The Linnaeus statue is truly majestic, and it is surrounded by four side figures symbolizing mineralogy, the plant kingdom, the animal kingdom, and fire. Bergstrand was present on the occasion of the inauguration of the grand Linnaeus statue on May 13, 1885, and recorded his impressions in his diary. Laurent graciously shared this excerpt from his great-grandfather's diary with a broader readership [24].

Another statue in the square of Humlegarden commemorates Carl Wilhelm Scheele (1742-1786). Laurent wrote a very interesting article about the scientist and about the story of the statue [25]. Scheele was a pharmacist and passed the examination required for managing a pharmacy, but never received an academic education: he was selftaught. At the age of 32, he was elected to be a member of the Royal Swedish Academy of Sciences, but attended the meetings of this august organization only once. He was involved in the discovery of more main-group elements than anybody else, including chlorine, manganese, barium, 


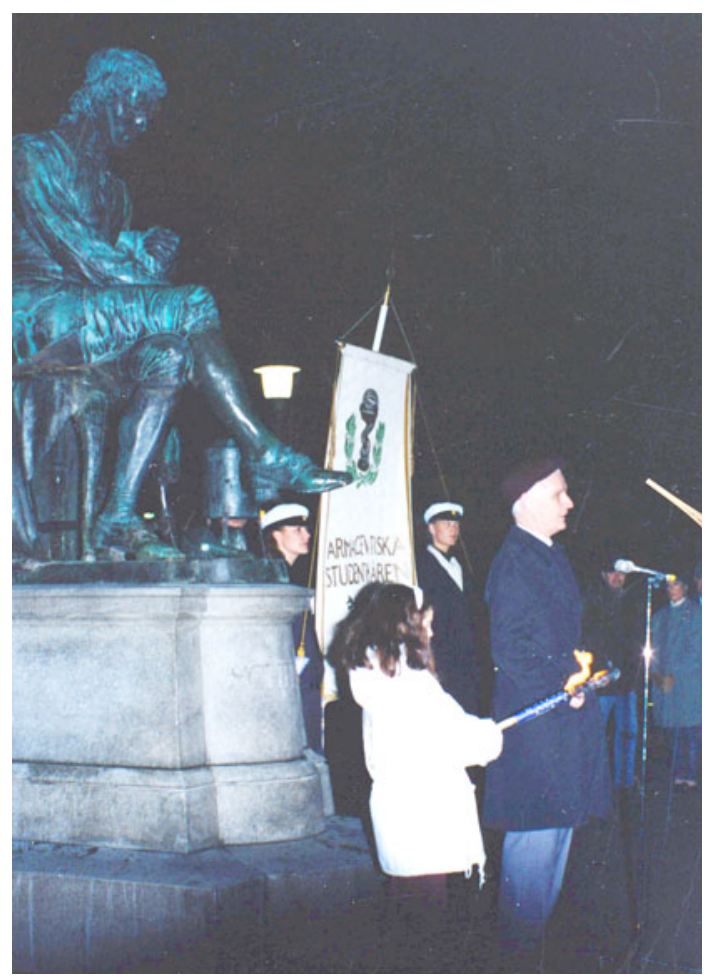

Fig. 10 Torvard Laurent speaks on December 6, 1992, in front of the Scheele statue

and others, and, of course, he is known as one of the discoverers of oxygen, along with Priestley and Lavoisier. Scheele has been depicted on stamps and in sculptures, but there is no authentic information about what he looked like. Laurent wrote about him in a factual way, which, however, read almost like a detective story. He augmented his text with the English translation of a poem by Count Carl Snoilsky, Sweden's foremost poet of the time of the inauguration of the Scheele statue, honoring the scientist. The translation was made jointly by Laurent and the Nobel laureate chemist and poet Roald Hoffmann [26] (Fig. 10).

Poem by Carl Snoilsky

for the inauguration of the Scheele statue

translated from the Swedish original

by Roald Hoffmann and Torvard Laurent

Quiet, modest, hidden from the world

You sat in your obscure corner

But from your labor at the hearth

A light spread, where there was only night

The square's noise is not from you,

A woody mount is best

And Linnaeus in Humlegården

Will have a worthy guest in you.

In the solid blend of metals

Sit with the crucible in your grove

Great seeker of the truth,
Searcher for matter's base

Bathe yourself in waves of air

Under the sighs of your tree

And when evening turns on its flames

Live on, in fire and light

Acknowledgments Our research is being supported in part by the Hungarian Scientific Research Foundation (OTKA No. K60365). This contribution was prepared during a visit at the Matrix Biology Institute (MBI) in Edgewater, New Jersey, supported by a generous travel fellowship from the MBI. I thank Dr. Vincent C. Hascall (Department of Biomedical Engineering, Cleveland Clinic) for his critical reading of the manuscript. The dedicated technical assistance of Joanne Caha (Edgewater, NJ) and Judit Szücs (Budapest) is much appreciated. I express my special thanks to Agneta Laurent (Stockholm) for collecting and lending me some precious images of Torvard C. Laurent and for her permission to reproduce them in this article.

\section{References}

1. Hargittai M, Hargittai I (2009) Torvard C. Laurent. In Hargittai M, Hargittai I Conversations with Hyaluronan Scientists (Volume 1 in Balazs EA, General Editor; Hyaluronan: From Basic Science to Clinical Applications. PubMatrix, Edgewater, NJ, pp 170-213; p 173

2. Laurent TC (2001) Carl-Erik Bergstrands studieresa i Tyskland 1859. Acta Academie Regie Scientiarum Upsaliensis. Libens Merito 21:267-280

3. Laurent TC (2000) Vivi Täckholm, née Laurent-family perspective. In Plant Systematics for the 21st Century. Wenner-Gren International Series No. 77. Portland Press, London, pp 13-19

4. Balazs EA, Laurent TC, Jeanloz RW (1986) Nomenclature of hyaluronic acid. Biochem J Lett 235:903

5. Balazs EA, Högberg B, Laurent TC (1951) The biological activity of hyaluronan sulfuric acid. Acta Physiol Scand 23: $168-178$

6. Laurent TC, Gergely J (1955) Light scattering studies on hyaluronic acid. J Biol Chem 212:325-333

7. Laurent TC (1957) The amorphous X-ray diffractogram of hyaluronic acid. Ark Kemi 11:513-518

8. Hargittai I, Hargittai M (2008) Molecular structure of hyaluronan: an introduction. Struct Chem 19:697-717

9. Laurent TC, Pietruszkiewicz A (1961) The effect of hyaluronic acid on the sedimentation rate of other substances. Biochim Biophys Acta 49:258-264

10. Hargittai I (2010) Alexander G. Ogston. In Volume 3, Balazs EA, ed, Selected contributions to the History of Hyaluronan Science. I Balazs EA, general ed, Hyaluronan: From Basic Science to Clinical Applications. PubMatrix, Edgewater, NJ (to be published)

11. Laurent TC, Killander J (1964) The theory of gel filtration and its experimental verification. J Chromatography 14:317-330

12. Minton AP (1995) Macromolecular crowding: A foreword. Biophys Chem 57:1-2

13. Balazs EA (2000) Why hyaluronan has so many biological activities. In Abatangelo G, Weigel PH (eds) New Frontiers in Medical Sciences: Redefining Hyaluronan. Elsevier Science B.V., pp 3-10, p 3

14. Laurent TC, Ogston AG (1963) The Interaction between Polysaccharides and Other Macromolecules. 4. The Osmotic Pressure of Mixtures of Serum Albumin and Hyaluronic Acid. Biochem J $89: 249-253$

15. Laurent TC (1989) Introduction. In The biology of hyaluronan. In: Ciba Foundation Symposium 143. Wiley, pp 1-5 
16. Pogany P, Kovacs A (2009) Conformational properties of the disaccharide building units of hyaluronan. Carbohydr Res 344:1745-1752

17. Scott JE, Cummings C, Brass A, Chen Y (1991) Secondary and tertiary structures of hyaluronan in aqueous solution, investigated by rotary shadowing-electron microscopy and computer simulation. Biochem J 274:699-705

18. Laurent TC, Hellsing K, Gelotte B (1964) Cross-linked gels of hyaluronic acid. Acta Chem Scand 18:274-275

19. Hargittai I (2002) Candid science II: conversations with famous biomedical scientists (edited by Magdolna Hargittai). Imperial College Press, London, p 406

20. Preston BN, Laurent TC, Comper WC, Checkler GJ (1980) Rapid polymer transport in concentrated solutions through the formation of ordered structures. Nature 287:499-503
21. Hargittai I $(2002,2003)$ The Road to Stockholm: Nobel Prizes, Science, and Scientists. Oxford University Press, Oxford, UK

22. Hargittai I, Laurent TC (eds) (2002) Symmetry 2000 Parts I and II Wenner-Gren International Series No. 80. Portland Press, London

23. Laurent TC (1998) The Chemistry, Biology and Medical Applications of Hyaluronan and Its Derivatives. Wenner-Gren International Series No. 72. Portland Press, London

24. Laurent TC (1999) Sculpture in Stockholm from the Memoirs of Carl-Erik Bergstrand. Chem Intell 5(4):51

25. Laurent TC (1999) What Did Carl Wilhelm Scheele Look Like? Chem Intell 5(3):28-30

26. Laurent TC (1999) What Did Carl Wilhelm Scheele Look Like? Chem Intell 5(3):29. The translation of the poem is reproduced with kind permission from Roald Hoffmann, Ithaca, New York 